\title{
Staphylococcus sp. PADA IKAN LAYANG (Decapterus russelii) ASAP Pinekuhe PRODUK KHAS SANGIHE
}

\author{
Ely John Karimela, Frans G Ijong dan Agnes T Agustin.
}

Fakultas Perikanan dan Ilmu Kelautan, Universitas Sam Ratulangi, Manado, Sulawesi Utara.

\begin{abstract}
ABSTRAK
Pinekuhe adalah istilah dalam bahasa Sangihe yang ditujukan kepada ikan layang asap tradisional yang unik. Studi ini difokuskan untuk menganalisis Staphylococcus sp., yang mengasosiasikan pinekuhe yang dijual dari pasar lokal, di kota Tahuna. Dalam penelitian ini metode yang digunakan yaitu metode eksploratif dan percontohan pinekuhe dilakukan untuk menganalisis jumlah total plate (TPC), jumlah staphylococci dan mengisolasi dan identifikasi Staphylococcus sp., yang terkait dengan produk. Hasil menunjukkan bahwa TPC sampel pinekuhe yang bervariasi selama waktu sampling

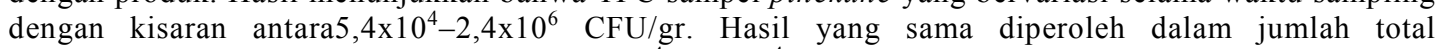
staphylococci dengan kisaran antara $2,4 \times 10^{4}-8,7 \times 10^{4}$ TVC/gr. Selanjutnya dilakukan isolasi dan identifikasi bakteri yang tumbuh pada media Manitol Salt Agar. Ada 66 isolat galur yang terkumpul, terdiri dari 55 isolat adalah Gram positif-coccus dan 11 isolat Gram-negatif. Selain itu, dari semua galur yang diisolasi yaitu ada 78,8\% yang diidentifikasi miliki genus Staphylococcus dengan karakteristik biokimia katalase positif dan semua galur isolate dapat mampu memfermentasi karbohidrat seperti sukrosa, glukosa, laktosa dan manitol.
\end{abstract}

Kata kunci: Pinekuhe, Staphylococcus, ikan Layang asap.

\section{PENDAHULUAN}

Pengasapan ikan merupakan salah satu metode pengawetan dan pengolahan yang telah banyak dimanfaatkan oleh masyarakat di Sulawesi Utara termasuk di daerah Sangihe. Pengolahan ikan dengan asap sebenarnya telah lama dikenal karena teknik pengolahanya, sederhana dan tidakmenggunakan teknologi dan biayanya murah. Menurut Adawyah, ( 2007 ) bahwa, pengasapan merupakan cara pengolahan atau pengawetan dengan memanfaatkan kombinasi perlakuan pengeringan dan pemberian senyawa kimia alami dari hasil pembakaran bahan bakar alami. Senyawa asap tersebut menempel pada ikan dan terlarut dalam lapisan air yang ada di permukaan tubuh ikan, sehingga terbentuk aroma dan rasa yang khas pada produk dan warnanya menjadi keemasan atau kecoklatan. Keanekaragaman produk olahan adalah berbagai jenis olahan yang dihasilkan dari kegiatan produksi baik dari budidaya maupun penangkapan sehingga produk tersebut memiliki daya guna dan nilai tambah dalam pemanfaatanya sehingga dijual hasil produk yang memberikan respon kepada konsumen. Salah satu pengolahan Ikan Asap khas daerah Sangihe yang disebut dengan Pinekuhe yang dibuat dari ikan layang Decapterus russelii yang bertujuan memperpanjang daya simpan, meningkatkan nilai ekonomis dan memenuhi pola konsumsi masyarakat yang cenderung menggunakan produk siap pakai.

Penikuhe merupakan ikan asap yang memiliki bentuk yang unik dan memiliki ciri khas yang sangat tradisional dan tidak ditemukan pada daerah lain di Indonesia. Penikuhe hanya terdapat di daerah Kepulauan Sangihe dan pada umumnya diolah secara tradisional, digemari oleh konsumen baik yang ada di Sangihe maupun di luar Sangihe. Produk olahan Pinekuhe termasuk perishable food (mudah rusak) sehingga memiliki daya awet yang terbatas dan tidak jarang terkontaminasi oleh bakteri patogen sebagai akibat dari rendahnya sanitasi dan higienis pada saat proses pengolahan.

Penelitian ini difokuskan pada aspek mikrobiologis secara khusus mengindentifikasi keberadaan bakteri Staphylococcus pada produk olahan ikan asap khas Daerah Sangihe Pinekuhe.

\section{METODOLOGI PENELITIAN}

\section{Bahan Baku}

Bahan baku utama yaitu produk olahan tradisional ikan asap Pinekuhe yang diambil secara acak di pasar Towoe, Tahuna Kab. Sangihe. 


\section{Tata Laksana Penelitian}

Sampel, dikemas dalam kertas steril/HVS kemudian plastik steril dan untuk mencegah agar sampel tidak terkontaminasi selama transportasi ke laboratorium, maka sampel ditempatkan dalam wadah tertutup (cool box) tanpa perlakuan es, dengan jarak waktu pengambilan berkisar antara 8-10 jam perjalanan (Tahuna-Manado).

Peralatan dan media yang digunakan dalam penelitian ini telah dipersiapkan terlebih dahulu untuk memudahkan dalam hal pengujian sampel uji. Pengamatan dan pengujian terhadap sampel ikan asap Pinekuhe hanya dilakukan terhadap daging, dimana jumlah sampel setiap kali pengamatan dan pengujian berjumlah minimal 6 sampel uji, dan pengambilan sampel dilakukan sebanyak 3 kali. Adapun uji mikrobiologis yang dilakukan menggunakan metode dimodifikasi oleh Ijong (2003).

1. Total Plate Count (TPC) dengan metode tuang dengan menggunakan media Nutrien Agar (NA) dan diinkubasi pada suhu 370C selama 24-48 jam.

2. Total Stapilokoki dengan metode sebar, menggunakan media Manitol Salt Agar (MSA), dan diinkubasi pada suhu $37^{\circ} \mathrm{C}$ selama 24-48 jam.

3. Isolasi dan penyediaan kultur sediaan dilakukan dengan cara menyeleksi koloni bebas yang tumbuh pada MSA dan menggoreskan pada NA miring diikuti dengan inkubasi pada suhu $37^{\circ} \mathrm{C}$ selama 24 jam.

4. Identifikasi didasarkan pada hasil uji biokimia (pewarnaan Gram, Uji Motility, uji Katalase, Uji Oksidase, Uji IMViC dan Uji Fermentasi Karbohidrat (Glukosa, Manitol, Sukrosa dan Laktosa) (Cappucino dan Sherman 1992).

\section{HASIL DAN PEMBAHASAN}

Hasil analisa TPC dan Total Stapilokoki terhadap sampel Pinekuhe seperti yang ditunjukkan pada Tabel 1 dan Tabel 2. Dari hasil ini dapat di lihat bahwa Pinekuhe pada pengambilan I-III yaitu semua sampel memiliki TPC relatif tinggi berkisar antara $6,7 \times 10^{4}$ $2,4 \times 10^{6} \mathrm{CFU} / \mathrm{g}$, jumlah ini lebih tinggi jika dibandingkan dengan persyaratan mutu yang dikeluarkan oleh Badan Standar Nasional Indonesia (SNI 2725 1:2009) dimana jumlah maksimum TPC ikan asap $1,0 \times 10^{5} \mathrm{CFU} / \mathrm{g}$. Berdasarkan data ini maka Pinekuhe tersebut tidak layak dikonsumsi secara langsung, tapi hanya dapat dikonsumsi apabila dilakukan pemasakan atau pemanasan terlebih dahulu. Pengolahan ikan asap ini biasanya belum menerapkan pengelolaan mutu secara baik. Hal ini disebabkan oleh beberapa faktor diantaranya adalah usaha dilakukan di lokasi yang memiliki sanitasi buruk (kawasan kumuh), tingkat pendidikan yang masih rendah, juga kurangnya kesadaran konsumen pada tingkatan ekonomi menengah ke bawah untuk membeli makanan yang sehat dan bergizi (Nastiti, 2006).

\begin{tabular}{|c|c|c|c|}
\hline Pengambilan & Sampel & $\begin{array}{c}\text { Nilai TPC } \\
\text { (CFU/g) }\end{array}$ & $\begin{array}{l}\text { Rata-rata Nilai } \\
\text { TPC ( CFU/g) }\end{array}$ \\
\hline \multirow{6}{*}{ I } & $\mathrm{A}$ & $3.4 \times 10^{5}$ & \multirow{6}{*}{$2.4 \times 10^{6}$} \\
\hline & B & $2.7 \times 10^{6}$ & \\
\hline & $\mathrm{C}$ & $2.5 \times 10^{5}$ & \\
\hline & $\mathrm{D}$ & $5.5 \times 10^{6}$ & \\
\hline & E & $2.3 \times 10^{6}$ & \\
\hline & $\mathrm{F}$ & $3.4 \times 10^{6}$ & \\
\hline \multirow{6}{*}{ II } & $\mathrm{A}$ & $3.2 \times 10^{6}$ & \multirow{6}{*}{$3.5 \times 10^{5}$} \\
\hline & B & $3.7 \times 10^{6}$ & \\
\hline & $\mathrm{C}$ & $2.1 \times 10^{6}$ & \\
\hline & $\mathrm{D}$ & $2.9 \times 10^{6}$ & \\
\hline & E & $2.6 \times 10^{5}$ & \\
\hline & $\mathrm{F}$ & $3.8 \times 10^{5}$ & \\
\hline \multirow{6}{*}{ III } & $\bar{A}$ & $2.9 \times 10^{5}$ & \multirow{6}{*}{$6.7 \times 10^{4}$} \\
\hline & $\mathrm{B}$ & $2.9 \times 10^{5}$ & \\
\hline & $\mathrm{C}$ & $2.1 \times 10^{6}$ & \\
\hline & D & $1.9 \times 10^{4}$ & \\
\hline & $\mathrm{E}$ & $2.5 \times 10^{5}$ & \\
\hline & $\mathrm{F}$ & $2.7 \times 10^{5}$ & \\
\hline
\end{tabular}

Nilai Total Stapilokoki memiliki kecenderungan yang sama dengan nilai TPC, seperti yang ditampilkan pada Tabel 2. Dari data ini dapat dilihat bahwa Pinekuhe, pada pengambilan I -III memiliki Total Stapilokoki relatif tinggi berkisar antara $2,4 \times 10^{4}-8,7 \times 10^{4}$ $\mathrm{TVC} / \mathrm{g}$. Analisa total Stapilokoki, bila dibandingkan dengan SNI-2725.1:2009 khususnya untuk Staphylococcus aureus dengan

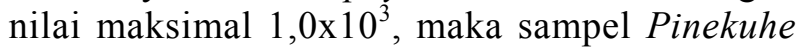
tidak memenuhi syarat. Tingginya nilai TPC dan Total stapilokoki kemungkinan dapat terjadi pada saat ikan diolah, disimpan dan pada saat didistribusikan ke konsumen, serta para penjual belum memperhatikan sanitasi dan higienis. Menurut Heruwati (2002), cara pengolahan yang kurang saniter dan higienis, serta penyimpanan dalam keadaan tidak dilindungi/dikemas dengan baik pada kondisi tropik, mengakibatkan produk ikan olahan tradisional sangat rentan terhadap kerusakan mikrobiologis. Ijong (2009), menambahkan 
Staphylococcus biasanya hidup sebagai parasit pada manusia dan hewan, kadang-kadang dapat menyebabkan infeksi serius. $S$. aureus dapat memproduksi enterotoksin yang menyebabkan keracunan makanan bagi manusia dan hewan. Hasil penelitian, Ijong (2004), menegaskan bahwa produk-produk olahan tradisional hasil perikanan pada umumnya terkontaminasi oleh S. aureus.

Tabel 2. Hasil Analisa Total Stapilokokidari ikan Asap Pinekuhe

\begin{tabular}{cccc}
\hline Pengambilan & Sampel & $\begin{array}{c}\text { Nilai Total } \\
\text { Stapilokoki } \\
\text { (TVC/gr) }\end{array}$ & $\begin{array}{c}\text { Rata-rata } \\
\text { Nilai Total } \\
\text { Stapilokoki } \\
\text { (TVC/gr) }\end{array}$ \\
\hline \multirow{6}{*}{ I } & A & $1.2 \times 10^{6}$ & \\
& B & $7.5 \times 10^{5}$ & \\
& C & $6.3 \times 10^{4}$ & $8.7 \times 10^{4}$ \\
& D & $1.5 \times 10^{6}$ & \\
& E & $1.7 \times 10^{6}$ & \\
& F & $1.6 \times 10^{4}$ & \\
& A & $6.6 \times 10^{4}$ & \\
II & B & $8.6 \times 10^{4}$ & \\
& C & $1.7 \times 10^{5}$ & $2.4 \times 10^{4}$ \\
& D & $1.2 \times 10^{4}$ & \\
& E & $7.9 \times 10^{5}$ & \\
& F & $3.2 \times 10^{5}$ & \\
& A & $3.2 \times 10^{5}$ & \\
& B & $7.3 \times 10^{5}$ & \\
& C & $1.4 \times 10^{5}$ & $6.7 \times 10^{4}$ \\
& D & $1.4 \times 10^{4}$ & \\
& E & $1.3 \times 10^{6}$ & \\
& F & $1.4 \times 10^{6}$ & \\
\hline $\mathrm{n}=6$ & & & \\
\hline
\end{tabular}

Karakteristik Biokimia Staphylococcus sp pada pewarnaan gram yaitu dari hasil uji perwarnaan gram yang telah dilakukan terhadap 66galur uji, diperoleh hasil 55 galur uji semuanya bakteri bersifat gram positif dan berbentuk kokus atau bulat dan 11 galur lainya bersifat gram negatif. Ijong (2003) menyatakan bahwa perbedaan struktur luar dinding sel bakteri gram positif dan negatif mengakibatkan terjadinya perbedaan warna pada akhir prosedur pewarnaan gram. Dari hasil uji oksidase bahwa hampir semua dari 55 galur memberikan respon reaksi negatif, hanya 4 galur saja yang memberikan reaksi positif. Hal ini berarti hampir semua galur tidak menghasilkan enzim sitokrome oksidase yang berperan dalam respirasi aerobik. Cappucino dan Sherman (1992), uji bersifat positif jika jika koloni berubah warna menjadi merah selanjutnya maron dan akhirnya menjadi kehitaman. Staphylococcus aureus memberi respon negatif. Hasil uji katalase yang telah dilakukan dari 55 galur uji yaitu 53 memberikan respon positif dan hanya 2 galur saja memberikan reaksi negatif atau tidak menunjukkan adanya gelembung $\mathrm{O}_{2}$. Ada sekitar $99 \%$ galur memproduksi enzim katalase. Enzim katalase atau periksodase sangat berperan dalam kelangsungan hidup mikroba. menurut Lay (1994), uji katalase berguna dalam identifikasi kelompok bakteri tertentu. Pada bakteri bentuk kokus, uji katalase digunakan untuk membedakan Staphylococcus dan Streptococcus. Kelompok Streptococcus memberi reaksi negatif, sedangkan Staphylococcus memberikan reaksi positif. Uji katalase ini dilakukan untuk mengidentifikasi kelompok bakteri bentuk kokkus, dalam membedakanStaphylococcus dan Streptococcus. Dimana kelompok Streptococcus bersifat katalase negatif dan Staphylococcus bersifat katalase positif.

Ijong (2003) menambahkan, pada saat mikroba melangsungkan respirasi secara aerobik, akan dihasilkan hidrogen peroksida $\left(\mathrm{H}_{2} \mathrm{O}_{2}\right)$ yang dapat bersifat racun bagi mikroba sehingga dapat mengakibatkan kematianya. Kecuali jika mikroba tersebut memiliki enzim katalase atau peroksidase yang mampu mendegradasi $\left(\mathrm{H}_{2} \mathrm{O}_{2}\right)$ menjadi $\mathrm{H}_{2} \mathrm{O}$ dan $\mathrm{O}_{2}$. Reaksi positif ditunjukan dengan adanya gelembung-gelembung gas $\left(\mathrm{O}_{2}\right)$ setelah dilakukan penambahan beberapa tetes $\mathrm{H}_{2} \mathrm{O}_{2} 3 \%$. Staphylococcus adalah bakteri bersifat aerob, katalase positif, yang membedakannya dengan Streptococccus (Ijong, 2009).

Tabel 3, mendiskripsikan karakteristik biokimia isolat Staphylococcus yang diisolasi dari sampel Pinekuhe. Berdasarkan hasil Uji biokimia 53 isolat teridentifikasi sebagai Staphylococcus sp., kecuali 2 isolat $(14,44)$, karena memberikan respon negatif terhadap uji katalase. Sebagian besar isolat mampu memfermentasi karbohidrat menghasilkan asam dan gas, sedangkan sebagian besar isolat memberikan respon negatif terhadap uji indol, Voges-Proskauer dan sitrat, tapi sebagian besar memberikan respon positif pada uji methyl-red.

\section{KESIMPULAN}

Total Plate Count dan Total Stapilokoki sampel Pinekuhe memiliki jumlah lebih tinggi jika dibandingkan dengan SNI, dengan kisaran TPC $5,4 \times 10^{4}-2,4 \times 10^{6} \quad \mathrm{CFU} / \mathrm{g}$ dan Total staphylococcus $\quad 2,4 \times 10^{4}-8,7 \times 10^{4} \quad \mathrm{TVC} / \mathrm{g}$. Staphylococcus merupakan bakteri yang dominan $(85,22 \%)$ mengkontaminasi produk Pinekuhe. 
Tabel 3. Karakteristik biokimia Isolat Staphylococcus yang di isolasi dari sampel ikan asap pinekuhe

\begin{tabular}{|c|c|c|c|c|c|c|c|c|c|}
\hline \multirow{2}{*}{ Kode Galur Uji } & \multirow{2}{*}{ Uji Katalase } & \multirow{2}{*}{ Uji Indol } & \multirow{2}{*}{ Uji MR } & \multirow{2}{*}{ Uji VP } & \multirow{2}{*}{ Uji Sitrat } & \multicolumn{4}{|c|}{ Uji Fermentasi Karbohidrat } \\
\hline & & & & & & Glukosa & Laktosa & Sukrosa & Manitol \\
\hline 1. C26 & $(+)$ & $(-)$ & $(+)$ & $(-)$ & $(-)$ & $\mathrm{A}$ & $\mathrm{A}$ & $\mathrm{A}$ & $\mathrm{A}$ \\
\hline 2. F26 & $(+)$ & $(-)$ & $(+)$ & $(-)$ & $(-)$ & A & $\mathrm{A}$ & $\mathrm{AG}$ & $\mathrm{AG}$ \\
\hline 3. A1A & $(+)$ & $(-)$ & $(+)$ & $(-)$ & $(+)$ & A & A & A & A \\
\hline 4. F1B & $(+)$ & $(-)$ & $(+)$ & $(-)$ & $(-)$ & A & $\mathrm{A}$ & A & A \\
\hline 5. $\mathrm{C} 14$ & $(+)$ & $(-)$ & $(+)$ & $(-)$ & $(-)$ & A & A & A & A \\
\hline 6. DA4 & $(+)$ & $(-)$ & $(+)$ & $(-)$ & $(-)$ & A & A & A & A \\
\hline 7. F13 & $(+)$ & $(-)$ & $(+)$ & $(-)$ & $(-)$ & A & $\mathrm{A}$ & A & A \\
\hline 8. C16 & $(+)$ & $(-)$ & $(+)$ & $(-)$ & $(-)$ & A & A & A & $\mathrm{AG}$ \\
\hline 9. EA4 & $(+)$ & $(-)$ & $(+)$ & $(+)$ & $(-)$ & A & $\mathrm{A}$ & A & - \\
\hline 10. BA5 & $(+)$ & $(-)$ & $(+)$ & $(-)$ & $(-)$ & A & A & A & - \\
\hline 11. A1B & $(+)$ & $(-)$ & $(+)$ & $(-)$ & $(-)$ & A & A & A & $\mathrm{AG}$ \\
\hline 12. EA6 & $(+)$ & $(-)$ & $(+)$ & $(-)$ & $(-)$ & A & A & $\mathrm{A}$ & - \\
\hline 13. C40 & $(+)$ & $(-)$ & $(+)$ & $(-)$ & $(-)$ & A & A & $\mathrm{AG}$ & A \\
\hline 14. BB4 & $(-)$ & $(-)$ & $(+)$ & $(-)$ & $(-)$ & A & $\mathrm{A}$ & - & A \\
\hline 15. C1A & $(+)$ & $(-)$ & $(+)$ & $(-)$ & $(-)$ & A & A & - & - \\
\hline 16. DB4 & $(+)$ & $(-)$ & $(+)$ & $(-)$ & $(-)$ & A & A & - & A \\
\hline 17. E2A & $(+)$ & $(-)$ & $(+)$ & $(-)$ & $(-)$ & A & A & - & A \\
\hline 18. B15 & $(+)$ & $(-)$ & $(+)$ & $(-)$ & $(-)$ & A & A & $\mathrm{AG}$ & $\mathrm{AG}$ \\
\hline 19. EB4 & $(+)$ & $(-)$ & $(+)$ & $(-)$ & $(-)$ & A & $\mathrm{A}$ & - & $\mathrm{A}$ \\
\hline 20. F23 & $(+)$ & $(-)$ & $(+)$ & $(-)$ & $(+)$ & A & $\mathrm{AG}$ & A & A \\
\hline 21.B13 & $(+)$ & $(-)$ & $(+)$ & $(-)$ & $(+)$ & A & $\mathrm{A}$ & A & A \\
\hline 22. B25 & $(+)$ & $(-)$ & $(+)$ & $(-)$ & $(-)$ & $\mathrm{A}$ & A & - & $\mathrm{AG}$ \\
\hline 23. C24 & $(+)$ & $(-)$ & $(+)$ & $(-)$ & $(-)$ & $\mathrm{AG}$ & A & A & A \\
\hline 24. F2A & $(+)$ & $(-)$ & $(+)$ & $(-)$ & $(-)$ & A & A & - & A \\
\hline 25. B2A & $(+)$ & $(-)$ & $(+)$ & $(-)$ & $(-)$ & A & A & A & A \\
\hline 26. A2B & $(+)$ & $(-)$ & $(+)$ & $(-)$ & $(-)$ & A & $\mathrm{AG}$ & A & A \\
\hline 27. B1B & $(+)$ & $(-)$ & $(+)$ & $(-)$ & $(+)$ & A & - & - & $\mathrm{AG}$ \\
\hline 28. B23 & $(+)$ & $(-)$ & $(+)$ & $(-)$ & $(+)$ & A & - & A & A \\
\hline 29. C2B & $(+)$ & $(-)$ & $(+)$ & $(-)$ & $(+)$ & A & $\mathrm{A}$ & - & $\mathrm{A}$ \\
\hline 30. A1A & $(+)$ & $(-)$ & $(+)$ & $(-)$ & $(-)$ & A & A & - & A \\
\hline 31. F1A & $(+)$ & $(-)$ & $(+)$ & $(-)$ & $(-)$ & A & A & A & A \\
\hline 32. EA3 & $(+)$ & $(-)$ & $(+)$ & $(-)$ & $(-)$ & A & $\mathrm{A}$ & A & A \\
\hline 33. $\mathrm{C} 2 \mathrm{~A}$ & $(+)$ & $(-)$ & $(+)$ & $(-)$ & $(+)$ & A & $\mathrm{AG}$ & A & A \\
\hline 34. EB1 & $(+)$ & $(-)$ & $(+)$ & $(-)$ & $(-)$ & A & $\mathrm{A}$ & A & A \\
\hline 35. B2B & $(+)$ & $(-)$ & $(+)$ & $(-)$ & $(-)$ & A & $\mathrm{A}$ & A & $\mathrm{A}$ \\
\hline 36. FA5 & $(+)$ & $(-)$ & $(+)$ & $(-)$ & $(-)$ & A & - & A & A \\
\hline 37. A2A & $(+)$ & $(-)$ & $(+)$ & $(-)$ & $(-)$ & A & & A & A \\
\hline 38. E2B & $(+)$ & $(-)$ & $(+)$ & $(-)$ & $(-)$ & A & - & A & A \\
\hline 39. D24 & $(+)$ & $(-)$ & $(+)$ & $(-)$ & $(+)$ & A & - & A & A \\
\hline 40. A23 & $(+)$ & $(-)$ & $(+)$ & $(-)$ & $(+)$ & A & A & A & A \\
\hline 41. D60 & $(+)$ & $(-)$ & $(+)$ & $(-)$ & $(-)$ & A & $\mathrm{A}$ & A & $\mathrm{A}$ \\
\hline 42. A14 & $(+)$ & $(-)$ & $(+)$ & $(-)$ & $(-)$ & A & A & A & A \\
\hline 43. C50 & $(+)$ & $(-)$ & $(+)$ & $(-)$ & $(-)$ & A & A & A & A \\
\hline 44. C40 & $(-)$ & $(-)$ & $(+)$ & $(-)$ & $(+)$ & A & A & A & A \\
\hline 45. F50 & $(+)$ & $(-)$ & $(+)$ & $(-)$ & $(-)$ & A & A & A & A \\
\hline 46. EB3 & $(+)$ & $(-)$ & $(+)$ & $(-)$ & $(-)$ & A & A & A & A \\
\hline 47. D14 & $(+)$ & $(+)$ & $(+)$ & $(-)$ & $(+)$ & A & $\mathrm{A}$ & A & A \\
\hline 48. F14 & $(+)$ & $(+)$ & $(+)$ & $(-)$ & $(-)$ & A & A & A & A \\
\hline 49. F23 & $(+)$ & $(-)$ & $(+)$ & $(-)$ & $(-)$ & A & A & A & A \\
\hline 50. D24 & $(+)$ & $(+)$ & $(+)$ & $(-)$ & $(-)$ & A & A & A & A \\
\hline 51. D13 & $(+)$ & $(-)$ & $(+)$ & $(-)$ & $(-)$ & A & A & A & A \\
\hline 52. E60 & $(+)$ & $(-)$ & $(+)$ & $(-)$ & $(-)$ & A & A & A & A \\
\hline 53. E40 & $(+)$ & $(-)$ & $(+)$ & $(-)$ & $(-)$ & A & A & A & A \\
\hline 54. A50 & $(+)$ & $(-)$ & $(+)$ & $(-)$ & $(-)$ & A & A & A & A \\
\hline 55. FA6 & $(-)$ & $(-)$ & $(+)$ & $(-)$ & $(-)$ & A & A & A & A \\
\hline
\end{tabular}

Ket.: $\mathrm{A}=$ Asam: $\mathrm{AG}=$ Asam dan Gas; $(-)=$ negatif; $(+)=$ positif.

\section{DAFTAR PUSTAKA}

Adawyah., 2007. Pengolahan dan Pengawetan Ikan., Prinsip Pengasapan., Bumi Aksara, Jakarta.
Anonimous. 1987. Ikan Asap. Lembaga Penelitian Dan Pengembangan. Universitas Sumatera Utara. Medan.

Cappucino J. G., dan Sherman N., 1992. Microbiology a Laboratory Manual. Third Edition. The 
Benjamin/Cummings Publishing Company. New York. USA.

Dwi Nastiti 2006., Kajian Peningkatan Mutu Produk Ikan Manyung (Arius Thalassinus) Panggang Di Kota Semarang. TESIS. Programn Pascasarjana Universitas Diponegoro Semarang.

Endang S. Heruwati. 2002., Pengolahan Ikan Secara Trdisional: Prospek Dan Peluang Pengembangan. Pusat Riset Pengolahan Produk Dan Sosial Ekonomi Kelautan Dan Perikanan, JL. K.S. Tubun Petamburan VI, Jakarta. JURNAL. Litbang Pertanian, Jakarta.

Foster T., 2004. Staphylococcus. http://www.medmicro. chapter12.

Giyatmi, Basmal J, Wijaya CH, Fardiaz S ., 2000. Dalam Pratama 2012., Karakteristik Beberapa Jenis Produk Ikan Asap di Indonesia. Tesis. Ps. Teknologi Hasil Perairan. Sekolah Passca sarjana. IPB.
Heller, B. 1980. Liquid Smoke Flavour Suited To Meat Products. Journal of Food Technology. (22): 4

Ijong F. G., 2003. Penuntun Praktikum Mikrobiologi Pangan Ikani. Lab. Mikrobiologi Hasil Perikanan. Fakultas Perikanan dan Ilmu Kelautan. UNSRAT. Manado.

Ijong F. G., 2004. Identifikasi Staphylococcus aureus pada produk fermentasi ikan di beberapa Pasar di kota Manado. Prosiding Perhimpunan Mikrobiologi cabang Sulawesi Utara. ISBN 979- 95236 - 5-VI., Hal 1-7.

Ijong F. G., 2009. Mikrobiologi Dasar. Edisi ke - empat. Bahan Kuliah Untuk Mahasiswa Program Sarjana ( S1 ). Fakultas Perikanan dan Ilmu Kelautan. UNSRAT. Manado.

Lay. B. W., 1994. Analisis Mikrobiologi di Laboratorium. PT. Rajawali Grafindo Persada. Jakarta. 